\title{
1 Temporal Variability in the Impacts of Particulate Matter on 2 Crop Yields on the North China Plain
}

4 Authors: Michael Wolffe ${ }^{a}$ (Corresponding author), Oliver Wilda, Stephen Longab, Kirsti Ashwortha

5 a Lancaster Environment Centre, Lancaster University, Bailrigg, Lancaster, LA1 4YW, United Kingdom

6 b Crop Sciences and Plant Biology, University of Illinois at Urbana-Champaign, 1206 W Gregory Dr, 7 Urbana, IL 61801, United States

8 Author Contributions

9 Michael Wolffe: Conceptualization, Methodology, Software, Validation, Formal Analysis, Investigation, Data Curation, Writing - Original Draft, Writing - Review \& Editing, Visualisation, Project Administration. Oliver Wild: Conceptualization, Methodology, Supervision, Writing - Review \& Editing. Stephen Long: Conceptualization, Supervision, Writing - Review \& Editing. Kirsti Ashworth: Conceptualization, Methodology, Resources, Writing - Review \& Editing, Supervision, Project Administration, Funding Acquisition.

Keywords: Diffuse Light, Crop Modelling, Aerosol Radiation Interactions, Air Pollution, PM

Abstract

The North China Plain (NCP) is a major agricultural region, producing $45 \%$ of China's maize. It is also vital to the Chinese economy, encompassing the Beijing-Tianjin-Hebei megacity region. Anthropogenic factors increasingly impact crop yields on the NCP, and globally. Particulate matter (PM) pollution is a significant problem in this region, where annual average PM concentrations over three times the Chinese national air quality standard were recorded for the Beijing-Tianjin-Hebei megacity region between 201318. PM absorbs light, reducing total shortwave radiation (SW), thereby limiting plant productivity. However, PM also scatters incoming SW, increasing the diffuse fraction, which has been shown to increase growth and biomass assimilation. 
The Joint UK Land Environment Simulator (JULES) crop model was used to assess the net impact of these competing changes in light on NCP maize yields. In contrast to some previous analyses, we find that PM-associated decreases in SW outweigh any positive impact on yield from an increasing proportion of diffuse radiation.

Furthermore, carbon allocation to different portions of the growing cropchanges during the development cycle. We find significant differences between the effect on final yield of identical changes to diffuse fraction and total SW occurring during different development stages. The greatest simulated yield gains from increased SW and reduced diffuse fraction, consistent with reductions in PM, are observed during the early reproductive stage of development (July-August), when the simulated gain of yield is as much as $12.9 \%$ more than in other periods.

To further assess the impact of PM-linked changes in SW and diffuse fraction on NCP crop yields, radiation profiles from different city regions were then applied across the NCP. The changes in SW associated with these city regions could increase maize yields across China by $\sim 8 \mathrm{Mt}$. This would completely offset China's annual maize imports, increasing both national and global food security.

\section{Introduction}

The North China Plain (NCP) is China's largest agricultural region, accounting for $61 \%$ of the country's wheat and $45 \%$ of its maize production (Yang et al. 2015). Today China is a major importer of wheat and maize (FAOSTAT, 2020). Increasing production in the NCP is therefore not only important for local farm economies, but also in reducing pressures on world grain markets. Maize production has risen twelvefold in the NCP over the last 6 decades(Li, 2009) and maize now comprises China's most important feedstock for livestock production (Shihuang and Kaijian, 2010).

Since the 1980s, climate change has begun to impact maize and wheat yields due to rising average temperature, only ameliorated by adoption of new crop varieties and better agronomic practices by producers (Liu YA et al., 2010, Han D. et al. 2018). The NCP includes the megacity region of Beijing- 
Tianjin-Hebei. Air pollution resulting from transportation, energy generation and industry in these major populations centres is known to affect crop yields (Feng et al., 2015; Masutomi et al., 2018) $\square$. One important component of air pollution is particulate matter (PM), which persists at high concentrations over the NCP. Annual average concentrations of PM2.5, i.e. particles with diameter $\leq 2.5 \mu \mathrm{m}$, of $108 \pm 34 \mu \mathrm{g}$ $\mathrm{m}^{-3}$ were recorded in Beijing-Tianjin-Hebei for 2013-18 (Zhai et al., 2019) $\square$. This far exceeds the international and national air quality guidelines for an average mean concentration of $10 \mu \mathrm{g} / \mathrm{m}^{-3}(\mathrm{WHO}$, 2015) $\square$ and $35 \mu \mathrm{g} / \mathrm{m}^{-3}$ (China: Air Quality Standards | Transport Policy, 2013) respectively. Such high levels of PM2.5 strongly affect both the intensity of short-wave (SW) radiation and the ratio of diffuse to direct SW radiation reaching the Earth's surface. PM occurs at high concentrations, not just in the NCP, but in many key crop growing regions around the world, particularly in developing nations. For example, the Indo-Gangetic Plain produces $\sim 50 \%$ of India's food (Dhillon et al, 2010, Timsina J, 2012). However, PM pollution in this region can reach $100 \mu \mathrm{g} \mathrm{m}^{-3}$ (Ojha N., et al. 2020), and is predicted to significantly reduce crop yields (Mina U. et al. 2018). The global nature of PM pollution, and its ubiquity and increase in key areas of global crop production has implications for global food security, making it critical to better quantify its impacts on crop yields.

PM is a heterogeneous mix of airborne particles, with highly variable chemical and physical properties. The particle composition, size distribution and altitude of aerosol govern how it interacts with SW radiation. For example, highly light absorbing particles, such as soot and black carbon from combustion of coal for heat in the winter, directly reduce total SW levels at the Earth's surface (Moosmüller, Chakrabarty and Arnott, 2009; Cohan et al., 2002) $\square$.

For well managed and watered crops, there is a linear relationship between absorbed SW radiation and crop biomass accumulation (Monteith, 1977; Dohleman \& Long, 2009); any reduction in incoming SW will therefore lower production. Reductions, such as those caused by PM, are exacerbated in so-called haze events, where atmospheric inversion results in an accumulation of pollutant at low altitude, strongly reducing surface SW (Aziz et al., 2019). Such haze events are a key cause of reduced visibility and surface SW in the North China Plains (Z. An et al., 2019; Han et al., 2012; Guo et al., 2014). Although most common in December and January, 5-6 haze days per month are also observed from April to September, the main period of maize production (Chen \& Wang, 2015). 
87 Other PM aerosol components such as sulphate are more reflective (Ramanathan et al., 2001) $\square$, scattering light instead of absorbing it. Intercepted light may be scattered in all directions by PM, both reducing SW reaching the surface and altering its angular distribution, increasing the proportion which is diffuse (Huang et al., 2014). Well-managed crops will typically form about a dense canopy of 5-7 $\mathrm{m}^{2}$ of leaves per $\mathrm{m}^{2}$ of ground. Direct beam sunlight is therefore largely intercepted by the uppermost leaves of crop plants, with most leaves below in shade (Wickens and Horn, 1972). In full sunlight, upper leaves intercept more light than they can use in photosynthesis, while photosynthesis is light-limited in the lower canopy (Ort et al. 2015) $\square$. Diffuse SW reaches the surface from all angles of the hemisphere, enabling it to penetrate deeper into crop canopies and allowing increased photosynthesis by the light-limited lower leaves. This more even distribution of radiation through the canopy under high levels of diffuse light reduces the risk of oversaturation and thus photo-inhibition in the upper canopy. This redistribution of light to other canopy layers increases radiation use efficiency (RUE) for the plant overall, improving the rates of carbon fixation, net canopy photosynthesis, and hence, gross primary production (GPP) in forest ecosystems (Roderick et al., 2001; Niyogi et al., 2004; Kanniah et al., 2012; Rap et al., 2015) $\square$ and is known as "diffuse light fertilisation" (Gu et al., 2002).

Variations in PM composition mean that changes in PM concentration do not strictly map to changes in surface radiation. This is compounded by variations in PM size distribution and meteorology which further affect how PM interacts with incoming radiation. Evidence for this can be seen in the widely fluctuating PM concentration over the year on the NCP. As PM concentration increases during the winter and declines in the summer, one would perhaps expect a relatively simple relationship where increased PM concentration directly maps to reduced radiation intensity at the earth's surface. However, aerosol optical depth (AOD), a key measure of the impact of total column aerosol on incoming radiation, peaks instead in late summer (Qu, Wang, Zhang, Sheng, \& Wang, 2016) due to the prevailing meteorological conditions at that time of year. Furthermore in winter, PM composition becomes increasingly black and organic carbon heavy, as combustion based power stations increasingly burn coal to provide heating during the winter months. This provides a marked difference in PM composition profile to the summer months when highly reflective nitrate aerosols dominate (Qu, Wang, Zhang, Sheng, \& Wang, 2016) $\square$, leading to different impacts on surface SW. These factors limit the power of PM concentration alone to explain changes in 
surface radiation.

117

Both field (Alton, North, \& Los, 2007; Gu et al., 2002; Niyogi et al., 2004; Strada, Unger, \& Yue, 2015) and modelling (Mercado et al., 2009; Rap et al., 2015; Roderick, Farquhar, Berry, \& Noble, 2001; Xie et al., 2020) $\square$ studies have attempted to quantify the impacts of PM on vegetation, providing strong evidence to support an increase in forest productivity, through increased surface diffuse light levels. A smaller number of studies suggest a similar result for crops (Cheng et al., 2015; Gu et al., 2002; Li \& Yang, 2015) $\square$. However, the magnitude of the benefit of increased proportions of diffuse light to croplands is disputed. While some studies suggest increased diffuse fraction due to air pollution (Cheng et al., 2015; Gu et al., 2002; Wang et al., 2015) $\square$ increases gross primary production of crops, others have found a reduction in predicted yields (Alton, 2008; Strada et al., 2015) $\square$. Greenwald et al. (2006), for example, predicted that crop yields may be reduced in a number of locations worldwide due to reductions in total radiation offsetting gains in RUE from a higher diffuse fraction.

A range of factors may account for the varying results in the studies outlined above, and these merit

further investigation. One example is that the timing of changes in total SW and diffuse fraction relative to crop development stage may impact yields. Crops progress through a series of characteristic developmental stages; from sowing, to vegetative growth, to seed filling to harvest, with carbon allocated in different proportions to different plant functions at each stage. Hence interventions to curb pollution, including PM, may be more or less impactful at different times within the crop life cycle.

Here, the Joint UK Land Environment Simulator-crop (JULES-crop) model is used to explore the effect of PM-mediated changes in light on maize yields across the NCP, and the sensitivity of the crops to the timing of these changes. As discussed above, the interaction of PM with surface radiation is complex, with concentration, composition and size distribution of the heterogenous mixture of PM particles all contributing to the eventual impacts of PM on surface SW. We therefore study the effects of changes in radiation directly, rather than considering fixed changes in PM concentration to determine how PMassociated changes in total magnitude and temporal variability of SW (light intensity) and diffuse fraction affect maize yields. 
146

147

Novelly, we conduct a range of sensitivity tests to explore the response of simulated maize yield to changes in total and diffuse SW, such as could result from policy interventions to reduce PM, at different crop development stages. This facilitates understanding of how PM pollution affects yield differently when it occurs at different development stages of our modelled crop. We then use time series of total SW and diffuse fraction from other large global cities with differing PM pollution to investigate the impacts of potential reductions in PM in the Beijing-Tianjin-Hebei region. Measurements of aerosol optical depth (AOD) and total cloud cover are then used to demonstrate that changes in diffuse fraction and total SW are linked to changes in PM. Furthermore, whilst previous authors (e.g. Greenwald et al., 2006) $\square$ have focused on cloud interactions with light, we use an average climatology to remove interannual variation in cloud cover, allowing us to focus on the influence of PM under more stable cloud conditions. We achieve this by manipulating SW and diffuse fraction, which we have shown to be strongly linked to aerosol optical depth and therefore PM pollution in this region.

This paper therefore aims to explore how radiation profiles associed with levels of PM found in other city regions may affect crop yields on the NCP, and to establish how targeted reductions in PM must take account of the crop life cycle to achieve improvements in yield. Exploration of the developmental state dependence of crop responses to PM linked radiation changes is key to ameliorating the impacts of PM on crop production.

\section{Materials and Methods}

\subsection{Model Set-Up}

JULES-crop has been demonstrated to accurately simulate maize yields at several well-characterized sites in the USA (Williams et al., 2017) $\square$, although it has not previously been tested in the NCP. The study domain $\left(31.0{ }^{\circ} \mathrm{N}, 113.0^{\circ} \mathrm{E}\right.$ to $\left.43.0^{\circ} \mathrm{N}, 123.0^{\circ} \mathrm{E}\right)$ spans a majority of the NCP including the BeijingTianjin-Hebei region. The MODIS AQUA-TERRA land cover product MCD12C1 was used to determine the cropped area of the NCP, which we assumed to be entirely given over to the major summer crop of this region, maize. JULES-crop, within the Joint UK Land Environment Simulator (JULES) model version 5.3 was used to simulate yields across the cropped area (Best et al., 2011; Clark et al., 2011; Osborne et 
al., 2015). We used the JULES-crop maize parameterization (Williams et al., 2017) with sowing dates taken from Sacks et al. (2010). Crops were assumed to be well irrigated in all simulations. Following the methodologies of Osborne et al. (2015),Williams et al. (2017) and Kimball et al. 2019, we convert the carbon allocated to the harvestable portion of the simulated maize crop to yield (dry t ha-1) .

Meteorological data of SW, downward long wave radiation, 2-m air temperature, precipitation, specific humidity, surface pressure and wind speed were taken from ERA-5 (European Reanalysis $5^{\text {th }}$ Generation) for $1981-2017$ at an hourly timestep and $0.25^{\circ}$ spatial resolution (Copernicus Climate Change Service (C3S), 2017). Diffuse radiation was calculated for each grid cell as the difference between the total and the direct incoming SW radiation at the surface as given by ERA-5. Just over $45 \%$ the grid-cells in the domain were assigned as maize using MODIS-terra land fraction products as given by ERA-5.

\subsection{BASE Simulation}

A climatological average driving dataset was obtained by calculating the mean of each meteorological variable of the ERA-5 driving data at an hourly timestep for each grid cell for 1981-2017. This was used to generate our baseline simulation (BASE) of maize production across the region. This average climatology reduces interannual variability in SW and diffuse fraction, and allows us to focus on average variations in SW and diffuse fraction and their relationship with one another. Perturbations are thereby compared to a more stable average baseline. Linear and multi-linear regression were used to derive the relationships between simulated yields and meteorological variables, and determine the relationships of diffuse fraction and total SW radiation with one another and with simulated yield.

To assess whether increased diffuse fraction increases maize yield across the NCP independent of changes in SW (as seen in previous studies; Rap et al., 2015; Roderick, Farquhar, Berry, \& Noble, 2001b; Wickens \& Horn, 1972), sensitivity tests were conducted in which the diffuse fraction was set to a constant value throughout the year, ranging from 0 and 1 , in increments of 0.1 . The above sensitivity tests and baseline results were used to generate relationships between total SW, diffuse fraction and maize yield. These calculated relationships (Figure 1) greatly informed the experiments detailed below. 
203

204

205

206

207

208

209

210

211

212

213

214

215

216

217

218

219

220

221

222

223

224

225

226

227

228

229

PM acts on incoming radiation in numerous and complex ways. Changes in concentration alone cannot be used as predictors of changes in radiation. Instead, the influence of PM speciation, size distribution, hygroscopicity and altitude, as well as meteorology must be considered both individually and in combination. Aerosol Optical Depth (AOD) on the other hand, has been demonstrated to be strongly linked to PM concentration (van Donkelaar, Martin, \& Park, 2006) $\square$, whilst also incorporating the interaction of PM and meteorology, thus providing a better indicator of the net impact of PM on surface radiation where concentration alone may lead to erroneous conclusions (Qu, Wang, Zhang, Sheng, \& Wang, 2016). AOD provides a measure of total column PM and its impact upon surface radiation (van Donkelaar et al., 2013; Just et al., 2015; Qu et al., 2016; Qin et al., 2018) $\square$. Least squares multilinear regression was applied (using the SKLearn python toolkit version 0.23.2) to AOD and total cloud cover (TCC), taken from the C3S meteorological datasets, to assess whether observed changes in SW and diffuse fraction on the NCP are driven by PM, cloud or both. The inclusion of TCC accounts for the impacts of PM on cloud formation, important given the contribution made by PM to cloud condensation, and thereby indirectly on incoming radiation. Our regression analysis was conducted using growing season average grid cell values of AOD, TCC, mean hourly daytime diffuse fraction for the growing season, mean hourly daytime downward SW radiation for the growing season, and final yield for the years 1997-2010.

\subsection{Sensitivity at Different Development Stages}

Varying meteorology and PM composition over the course of the year alter average total SW and diffuse fraction profiles across the NCP. The maize crop progresses through a series of development stages, characterised by different rates of photosynthesis and carbon allocation between roots, stems, leaves and reproductive structures. The impact of varying profiles of SW and diffuse fraction can therefore affect crop yields differently depending on when during the season perturbations to light occur. We conducted a range of sensitivity tests to assess how the timing of changes to the diffuse fraction and intensity of light relative to crop development stage affects final yield.

Post emergence, the crop develops through the vegetative stage and reproductive stage, each 
subdivided into early and late in JULES, giving four stages overall. Increased levels of PM during each development stage were simulated by elevating the diffuse fraction of our BASE simulation by $50 \%$ for a given stage, and decreased levels of PM by reducing diffuse fraction by $50 \%$. The relationship shown in Figure 1. was then used to deduce the total SW for each timestep consistent with the altered diffuse fraction. We refer to total SW modified in this manner as "diffuse-corrected" SW. All other driving variables remain unchanged from BASE. The statistical significance of yield results were determined by related ttest using the SciPy Stats module ttest_rel function across the cropped area of the model domain.

\subsection{Impact of City Radiation Profiles on Yields}

To investigate timing effects further, and as a proxy for potential future changes in PM concentration and composition, we studied the impacts on NCP crop yields of light profiles from the regions surrounding four global cities (New York, Madrid, Delhi, and Cairo), and one city in the NCP (Beijing).

These cities were chosen for their differing PM profiles and locations. Beijing experiences higher PM2.5 pollution (108 $\pm 34 \mathrm{\mu g} \mathrm{m}^{-3}$ for 2013-18, Zhai et al., 2019) than Madrid (12.1 $\mathrm{\mu g} \mathrm{m}^{-3}$ for the urban background from 2004-2009, Karanasiou et al., 2014) and New York (12.3 $\mu \mathrm{g} \mathrm{m}^{-3}$ for the period 20052016 (Peltier et al., 2011)), but is located at a comparable latitude (Beijing: $39.9^{\circ} \mathrm{N}$; New York: $40.7^{\circ} \mathrm{N}$; Madrid: $40.4^{\circ} \mathrm{N}$ ). Conversely, Delhi experiences seasonally higher levels of PM pollution than Beijing (varying from a minimum concentration of $46 \mu \mathrm{g} \mathrm{m}^{-3}$ to a maximum of $279 \mu \mathrm{g} \mathrm{m}^{-3}$ over the year; Gorai. A, et al. 2018) but is located at a considerably lower latitude than Beijing. We therefore use Cairo (30.0 $\left.{ }^{\circ} \mathrm{N}\right)$ as a comparator for Delhi $\left(28.7^{\circ} \mathrm{N}\right)$ due to its similar latitude but lower PM pollution $\left(51 \mathrm{\mu g} \mathrm{m}^{-3}\right.$ in 2013 , Boman et al., 2013), serving to illustrate how the meteorology and pollution profiles over Delhi city region limit the potential surface SW in the region. Whilst the levels of PM in New York and Madrid are substantially lower than those for Beijing and the NCP, large scale PM reductions across the NCP are likely and possible given the trajectory of PM concentrations over the last 7 years. We therefore present this city analysis as a way to explore how SW and diffuse fraction and therefore crop yields could change in the near future. They should be seen as an exploration of possibility space in terms of the outcomes of PM linked changes to SW and diffuse fraction, not an explicit prediction for what the future will definitively look like. 
Average hourly diffuse fractions (taken from the 37-year ERA-5 dataset) from each city, were used to drive JULES-Crop over the model domain. The resulting yields on the model domain using SW and diffuse fraction profiles from four global city regions were compared to those obtained using the diffuse fraction for Beijing, and to our climatological average BASE case. The climatological average total SW for each city region was then applied in conjunction with the climatological average diffuse fraction time series to simulate the net effects of these different city PM regimes on NCP maize yields.

To disentangle the opposing effects of changes in SW and diffuse fraction on yield, we ran two further simulations for each city to demonstrate: 1) the levels of SW that would be found to occur in each city given the diffuse fraction at that time in the NCP, 2) the potential impacts of an altered relationship between SW and diffuse fraction, which can be partially attributed to changing levels of PM. In the first simulation, the mean diffuse fractions for the NCP domain were applied to each grid cell (as per BASE), with the total SW for that grid cell, derived from the relationship between diffuse and total SW for that city (named CITY_mod_SW simulations). In the second simulation, mean total SW for the NCP domain was applied to each grid cell (as per BASE), and the diffuse fraction for that grid cell was derived from the relationship between diffuse and total SW for that city (CITY_mod_Diff simulations). These simulations superimpose the relationship between SW and diffuse fraction in other city regions over the NCP. As this relationship between total and diffuse SW is strongly linked to levels of cloud and aerosol, if can be considered a proxy to describe the effects of changing profiles of SW and diffuse fraction over the year on the NCP.

\section{Results}

\subsection{Aerosol Optical Depth (AOD) Results}

We found the strongest correlation between changes in AOD and total cloud cover (TCC) with diffuse fraction $\left(R^{2}=0.90\right)$, whilst changes in AOD and TCC explained just under $40 \%$ of variation in total SW. AOD alone was found to explain $80 \%$ of changes in diffuse fraction but only $15 \%$ of changes in total SW. This suggests that of the variability in SW resulting from changes to cloud and aerosol, an average of $38 \%$ comes from aerosol alone ( $R^{2}$ for aerosol alone divided by $R^{2}$ for aerosol + total cloud cover). We conclude that whilst the observed changes in light intensity in the domain are mainly driven by cloud 
cover, changes to AOD, linked to PM pollution, make a non-negligible contribution to light intensity, and a large contribution to changes in diffuse fraction. Further sensitivity tests presented here, in which we modify light intensity (SW) and/or diffuse fraction, should therefore be seen as an exploration of potential changes in maize yields if PM concentrations were to change across the NCP.

\subsection{The BASE Simulation}

\subsubsection{Relationships}

We found light to be the most critical meteorological variable for predicting simulated maize yield in our baseline simulation (BASE). Yield was positively correlated with mean hourly SW such that a $10 \%$ increase in light intensity correlated with an $8 \%$ increase in yield $\left(R^{2}=0.54\right.$, Figure $\left.1 . i\right)$. However, we found yield to be negatively correlated with mean hourly diffuse fraction with a $10 \%$ increase in diffuse light reducing yield by $9 \%$ ( $R^{2}=0.49$, Figure 1 .ii). While this may initially appear counterintuitive, it is driven by the strong negative logarithmic relationship between grid cell average total SW and diffuse fraction $\left(R^{2}=0.85\right)$ for the domain during the growing season (Figure 1.iii.), therefore reproducing the negative impacts of reduced SW from increased PM cover reported in previous studies (Gu, Wang, Zhuang, \& Han, 2018; Zhou, Chen, \& Tian, 2018). A 10\% increase in the mean growing season diffuse fraction (i.e. from 0.49 to 0.54 ) on the NCP corresponds to a reduction in average SW of $72 \mathrm{~W} \mathrm{~m}^{-2}$.
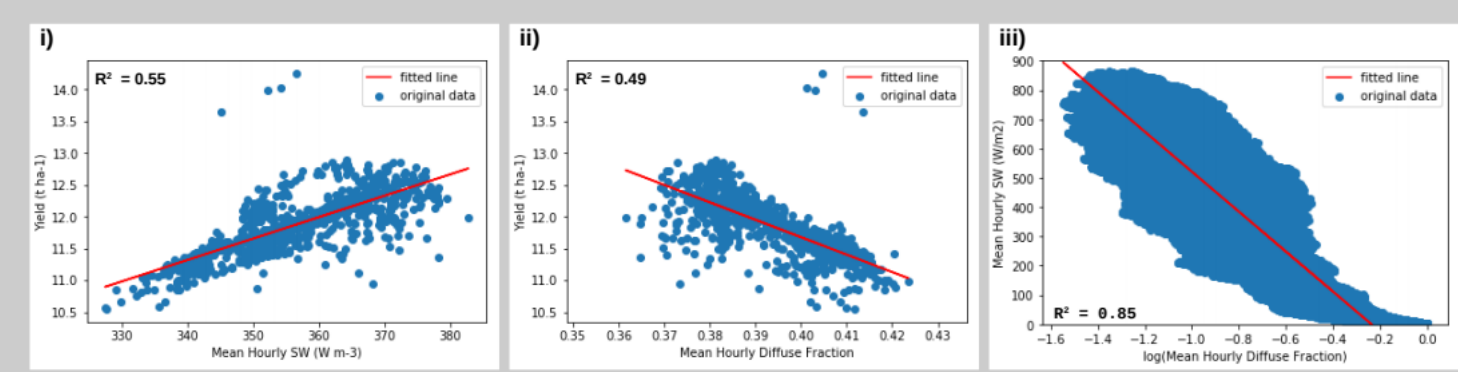

Figure 1) i) Maize yield versus BASE average hourly SW in grid cells with saturated soil, ii) BASE average hourly diffuse fraction vs yield in saturated soil grid cells iii) BASE SW vs diffuse fraction for all grid-cells

The relationship between diffuse fraction and yield was non-linear for constant total SW. Increasing diffuse fraction by $10 \%$ relative to the growing season mean increased simulated maize yield by $0.007 \mathrm{t}$ $\mathrm{ha}^{-1}$, while a $10 \%$ decrease reduced yield by $0.035 \mathrm{t} \mathrm{ha}^{-1}$. These changes, associated with changing diffuse fraction, represent less than a $0.1 \%$ change in yield, whereas a $10 \%$ increase in average total SW 
led to a yield gain of $1.05 \mathrm{t} \mathrm{ha}^{-1}$, a change 150 times greater. We conclude therefore that the diffuse light

311 fertilisation effect is insignificant in comparison to the effects of reducing total SW.

\section{$312 \quad 3.2 .2$ Yields}

313 The average yield predicted across the NCP was $11.9 \pm 0.5 \mathrm{t} \mathrm{ha}^{-1}$, using the 37-year climatological 314 average driving data derived from ERA-5. In 2011, the recorded yield for maize in China was $5.75 \mathrm{t} \mathrm{ha}^{-1}$

315 (Hu and Zimmer, 2013), just under half the modelled yield produced in our BASE simulation. Without 316 irrigation however, the modelled average yield is $6.73 \mathrm{tha}^{-1}$. Furthermore, we made the assumption that 317 maize is grown across all cropped land in the model domain, whereas in reality the most favourable areas

318 for crop production are currently reserved for other crops. This results in a further positive skew of 319 average maize yield in our simulations.

320

321 To ensure that light effects are not confounded with other environmental limitations, we continue to apply 322 irrigation in all simulations comparing results against the (irrigated) BASE simulation. The projected yields 323 for all model simulations are shown in Table 1. The cropped area and yields for BASE, along with the 324 average SW and diffuse fraction across the domain, are shown in Figure 2. Table 1 provides a reference 325 for the wide range of potential yields that might be expected under the SW and diffuse fraction scenarios 326 explored in this work. 


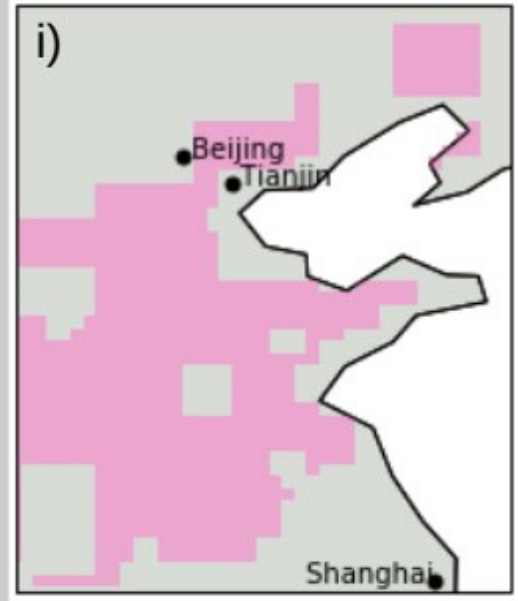

Cropped Area
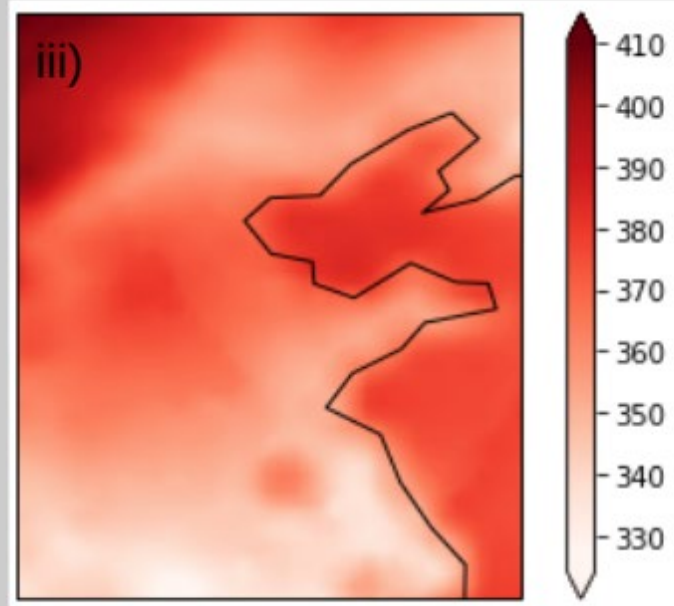

Average Growing Season Hourly SW $\left(\mathrm{W} \mathrm{m}^{-1}\right)$
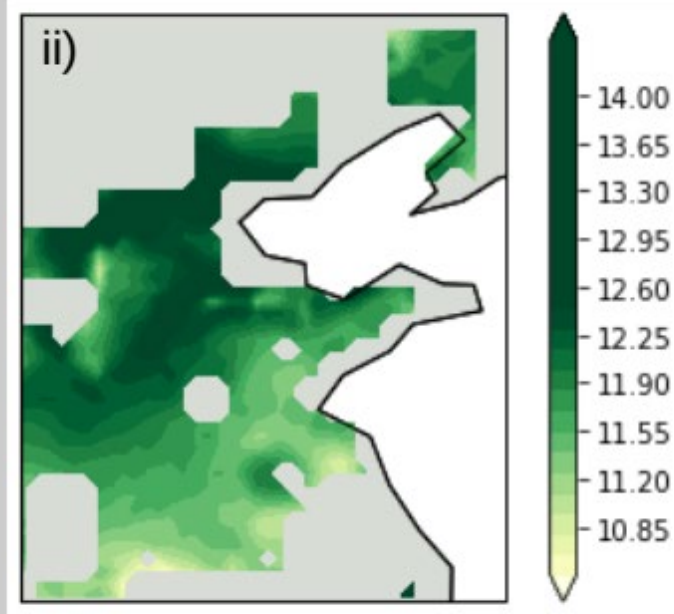

Maize Yield $(\mathrm{t} \mathrm{ha-1})$

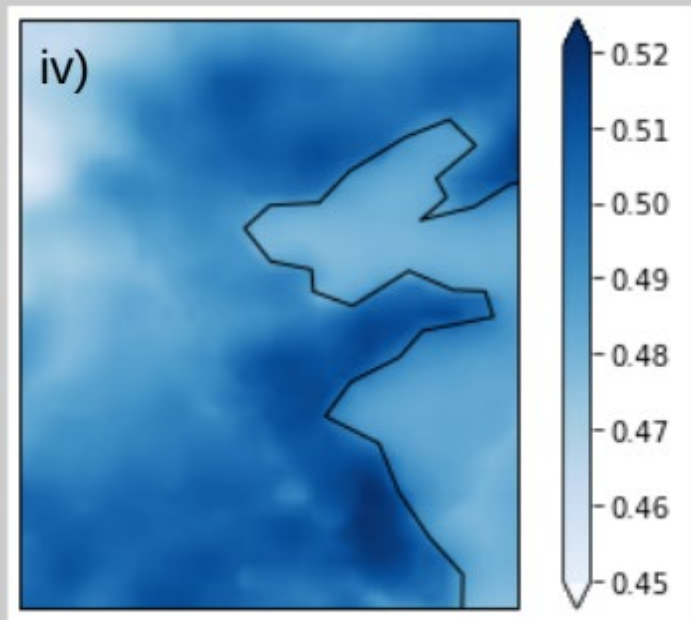

Average Growing Season Hourly Diffuse Fraction 
Figure 2) i) Cropped region of the NCP in model, ii) BASE model yield output (t ha-1), iii) Average Growing Season Day time Hourly

332 Spatial variation in maize yield across the NCP in BASE was highly related to the strong negative 333 logarithmic relationship between SW and diffuse fraction. In the BASE_Diff simulations, where diffuse 334 fraction was increased without a change in total SW, maize yield slightly increased due to the diffuse light 335 fertilisation effect, as reported for a variety of crops in previous modelling and observational studies 336 (Mercado et al., 2009; Brodersen and Vogelmann, 2010; K. Huang et al., 2014; Rap et al., 2015, 2018; 337 Yue and Unger, 2017) $\square$. However, as shown in Figure 1, this relationship is not observed for our BASE case (Figure 1.i.). This is due to the observed reduction of SW with increasing diffuse fraction In Figure 339 1.iii. 


\begin{tabular}{|c|c|c|c|}
\hline Run \# & Name & $\begin{array}{l}\text { Average Yield } \pm \text { Standard } \\
\text { Deviation }\left(\mathrm{t} \mathrm{ha} \mathrm{h}^{-1}\right)\end{array}$ & $\begin{array}{l}\text { Percentage Difference } \\
\text { from BASE (\%) }\end{array}$ \\
\hline 1 & BASE & $11.9 \pm 0.5$ & $\mathrm{~N} / \mathrm{A}$ \\
\hline 2 & BASE_Diff_0.0 & $10.2 \pm 0.5$ & -14.1 \\
\hline 3 & BASE_Diff_0.1 & $10.7 \pm 0.5$ & -9.8 \\
\hline 4 & BASE_Diff_0.2 & $11.2 \pm 0.5$ & -5.9 \\
\hline 5 & BASE_Diff_0.3 & $11.6 \pm 0.5$ & -2.4 \\
\hline 6 & BASE_Diff_0.4 & $11.9 \pm 0.5$ & 0.6 \\
\hline 7 & BASE_Diff_0.5 & $12.3 \pm 0.5$ & 3.1 \\
\hline 8 & BASE_Diff_0.6 & $12.4 \pm 0.5$ & 5.3 \\
\hline 9 & BASE_Diff_0.7 & $12.8 \pm 0.5$ & 7.0 \\
\hline 10 & BASE_Diff_0.8 & $12.8 \pm 0.5$ & 8.4 \\
\hline 11 & BASE_Diff_0.9 & $12.3 \pm 0.5$ & 9.5 \\
\hline 12 & BASE_Diff_1.0 & $12.9 \pm 0.5$ & 10.1 \\
\hline 13 & BJG, Diff & $11.9 \pm 0.5$ & 1.1 \\
\hline 14 & MAD, Diff & $11.4 \pm 0.5$ & -34.2 \\
\hline 15 & NYC, Diff & $11.7 \pm 0.5$ & 7.1 \\
\hline 16 & DEL, Diff & $11.7 \pm 0.5$ & -17.6 \\
\hline 17 & CAI, Diff & $11.2 \pm 0.5$ & -31.7 \\
\hline 18 & BJG_SW, Diff & $12.1 \pm 0.4$ & 2.5 \\
\hline 19 & MAD_SW, Diff & $15.2 \pm 1.2$ & 28.9 \\
\hline 20 & NYC_SW, Diff & $12.6 \pm 0.4$ & 5.7 \\
\hline 21 & DEL_SW, Diff & $11.9 \pm 0.5$ & -0.1 \\
\hline 22 & CAI_SW, Diff & $15.9 \pm 2.1$ & 34.2 \\
\hline 23 & BJG_Mod_Diff & $11.7 \pm 0.5$ & -1.1 \\
\hline 24 & MAD_Mod_Diff & $11.6 \pm 0.5$ & -3.0 \\
\hline 25 & NYC_Mod_Diff & $11.7 \pm 0.5$ & -1.7 \\
\hline 26 & DEL_Mod_Diff & $11.6 \pm 0.5$ & -3.2 \\
\hline 27 & CAI_Mod_Diff & $11.6 \pm 0.5$ & -3.2 \\
\hline 28 & BJG_Mod_SW & $11.9 \pm 0.7$ & 1.1 \\
\hline 29 & MAD_Mod_SW & $7.9 \pm 0.7$ & -34.2 \\
\hline 30 & NYC_Mod_SW & $12.6 \pm 0.5$ & 7.1 \\
\hline 31 & DEL_Mod_SW & $9.8 \pm 0.7$ & -17.6 \\
\hline 32 & CAI_Mod_SW & $8.1 \pm 0.5$ & -31.7 \\
\hline 33 & DEV1_0.5 & $13.3 \pm 0.9$ & 6.6 \\
\hline 34 & DEV2_0.5 & $13.5 \pm 1.4$ & 8.3 \\
\hline 35 & DEV3_0.5 & $15.9 \pm 1.4$ & 28.2 \\
\hline 36 & DEV4_0.5 & $15.1 \pm 1.2$ & 21.6 \\
\hline 37 & DEV1_1.5 & $8.4 \pm 1.2$ & -33.1 \\
\hline 38 & DEV2_1.5 & $8.2 \pm 1.1$ & -33.5 \\
\hline 39 & DEV3_1.5 & $7.9 \pm 0.7$ & -37.3 \\
\hline 40 & DEV4_1.5 & $9.5 \pm 0.9$ & -24.4 \\
\hline
\end{tabular}

Table 1. Summary of key model results from simulations. Average yield is colour coded such that the average yield for BASE is the 
347 BASE simulations provide a climatological average for comparison of sensitivity tests to a reasonable baseline scenario.

348

349

BASE - a simulation using the climatological average meteorological driving data

350

BASE_Diff_x - Uses climatological average meteorological driving data, excepting diffuse fraction, which was set to a fixed fraction

(x). This baseline scenario provides a benchmark to demonstrate the effects of diffuse fraction modification alone.

353

BJG , MAD, New York, DEL, CAI - Beijing, Madrid, New York City, Delhi, Cairo

355

CITY simulations are used to illustrate potential future scenarios for yield on the NCP with changing SW radiation profiles.

357

CITY, Diff - As BASE, but with diffuse fraction from CITY across all grid cells for each timestep.

CITY_SW, Diff - As BASE, but with SW and diffuse fraction from CITY across all grid cells for each timestep

CITY_Mod simulations are used to present the relationship between diffuse fraction and SW found at CITY in the context of the

NCP as a proxy for the differing conditions and PM profiles found at each CITY region.

364

CITY_Mod_Diff - As BASE, but with diffuse fraction derived from NCP SW using the relationship between SW and diffuse fraction found at the CITY.

367

368

CITY_Mod_SW - As BASE, but with SW derived from NCP diffuse fraction using the relationship between SW and diffuse fraction found at the CITY.

370

DEV simulations test crop sensitivity to changes in SW and diffuse fraction during different crop development stages.

DEV1, DEV2, DEV3, DEV4 - Early vegetative phase, late vegetative phase, early reproductive phase, late reproductive phase

DEVZ_0.5 - As BASE, but with diffuse fraction decreased by $50 \%$ for development stage Z, with SW set to "diffuse corrected" SW.

\section{$378 \quad 3.3$ Sensitivity at Different Development Stages}

379 The timing of the changes in SW and diffuse fraction made significant differences to final maize yield. We 
reproductive stage (DEV3). Increased diffuse fraction and reduced SW (representative of an increase in

382 PM concentrations) during this period have the most significant effect, reducing yields by an average $37 \%$ compared to BASE (Paired t-test, $t=-5.73, p=0.001$ ). Conversely, reducing diffuse fraction and increasing

384 SW (simulating reduced PM) during DEV3 led to a $28 \%$ increase in average yield (Paired $t$-test, $t=-6.46$,

385

386

387

388

389

390

391

392

393

394

395

396

397 $\mathrm{p}=0.001$ ). Applying the same changes to light intensity (total $\mathrm{SW}$ ) and diffuse fraction during other development stages had a lower impact. For example, simulating reduced PM during the early vegetative stage (DEV1) increased yields by only $7 \%$, less than one-fifth of the impact for DEV3 (again, the difference here is significant, $t=-5.78, p=0.001)$. However, the difference between yields when diffuse fraction is reduced in the early and late reproductive phase was not found to be significant $(\mathrm{t}=-2.49$, $p=0.139)$, and neither was the difference between increasing diffuse fraction in the vegetative or early reproductive phase. This indicates that changes in radiation during the early reproductive phase produce the most sizable increases in maize yields, but that increasing ambient SW radiation by reducing the level of PM during the late reproductive phase would also be beneficial.

\subsection{Impact of City Radiation Profiles on Yields}

The global city regions used to simulate crop yields if PM was to change across the NCP, are summarised in Table 2 below. 


\begin{tabular}{|l|l|r|r|r|r|}
\hline Location & \multicolumn{1}{|c|}{ Coordinates } & $\begin{array}{c}\text { Average } \\
\text { Hourly SW } \mathbf{~} \mathbf{W} \\
\mathbf{m}-2)\end{array}$ & $\begin{array}{c}\text { Average Hourly } \\
\text { Diffuse Fraction }\end{array}$ & Average AOD & PM2.5 $(\boldsymbol{\mu g} \mathbf{~ m - 3 )}$ \\
\hline NCP & $\begin{array}{l}31.0 \mathrm{~N}, 113.0 \mathrm{E} \text { to } \\
43.0 \mathrm{~N} \text { to } 123 \mathrm{E}\end{array}$ & 363.5 & 0.49 & 0.37 & $62.5-92.7$ \\
\hline Beijing & $39.9^{\circ} \mathrm{N}, 116.4^{\circ} \mathrm{E}$ & 365.6 & 0.51 & 0.28 & 108.0 \\
\hline Madrid & $40.4^{\circ} \mathrm{N}, 3.7^{\circ} \mathrm{W}$ & 453.2 & 0.37 & 0.15 & 12.1 \\
\hline $\mathrm{NYC}$ & $40.7^{\circ} \mathrm{N}, 74^{\circ} \mathrm{W}$ & 377.6 & 0.42 & 0.20 & 12.3 \\
\hline Delhi & $28.7^{\circ} \mathrm{N}, 77.1^{\circ} \mathrm{E}$ & 408.5 & 0.44 & 0.38 & $46.0-279.0$ \\
\hline Cairo & $30.0^{\circ} \mathrm{N}, 31.2^{\circ} \mathrm{E}$ & 547.8 & 0.33 & 0.17 & 51.0 \\
\hline
\end{tabular}

400

401

402

403

404

405

406

407

408

409

410

411

412

413

414

415

416

417

418

419

420

421

422

423

424

425

Table 2. Indicative values for average SW, diffuse fraction and PM2.5 concentration for NCP study region and for city regions studied.

Average hourly SW and diffuse fraction are taken from the climatology (generated from 1979-2017 ERA-5 meteorological data) used to drive all city runs for the growing season of modelled maize crop.

$\mathrm{AOD}$ is an average value, taken from the C3S climate data store meteorological dataset for aerosol optical depth, for the city containing grid cell, for the months April to September (inclusive of growing season), from 1997-2010

PM2.5 data is taken from a range of ground-based studies conducted during the timeframe of this modelling study. Though the PM concentrations are not always overlapping in time in many cases, this serves as an indicator of representative values within the period of the climatology.

a). Yao. L, et al., 2016 (range given for average seasonal values) b). Zhai. S, et al., 2019, c). Santurtun, A, et al., 2015, d). Shmoo, J.L.C., et al., 2016, e). Jain, S.L., et al., 2005, (range given for average seasonal values) f). Khoder, M.I., et al., 2009

When values of SW and diffuse fraction taken from Beijing city were applied across the domain, yields did not differ significantly from those obtained using SW and diffuse fraction for the whole of the NCP domain. All other city comparison runs discussed in this section are compared to yields from Beijing (BJG) simulations rather than BASE, because the different spatial distribution of SW and diffuse fraction in BASE would make such comparison inappropriate.

The greatest change from our Beijing-based simulations was found in applying values for Cairo to the NCP. CAI_Diff (i.e. NCP domain SW but Cairo diffuse fraction) simulated yields $34 \%$ lower than those of BJG_Diff (Figure 3.e.i), mostly attributable to average diffuse fraction in Cairo being $35 \%$ lower than that in Beijing during the growing season. Application of diffuse fractions from New York, Madrid and Delhi to the NCP (New York_Diff, MAD_Diff, DEL_Diff simulations) reduced yields by an average of 1, 5 and $1 \%$ respectively due to slightly lower annual average diffuse fractions $(0.42,0.37$ and 0.44 , respectively) reducing diffuse light fertilisation effects. 
427 However, when both diffuse and total SW were modified to reflect the average conditions in each city, the

428

429

430

431

432 higher average annual SW at New York, Madrid and Cairo more than compensates for their relatively lower diffuse fraction, with yields increases in New York_SW_Diff, MAD_SW_Diff and CAI_SW_Diff simulations by $3 \%, 26 \%$ and $30 \%$ respectively (Figure 3.c,e,ii). Although SW and diffuse fraction are substantially different at Delhi from Beijing, DEL_Diff and DEL_SW_Diff (described in section 2.5) show little change in yield from BJG_Diff $(-1 \%)$ and BJG_SW_Diff $(-3 \%)$ respectively.

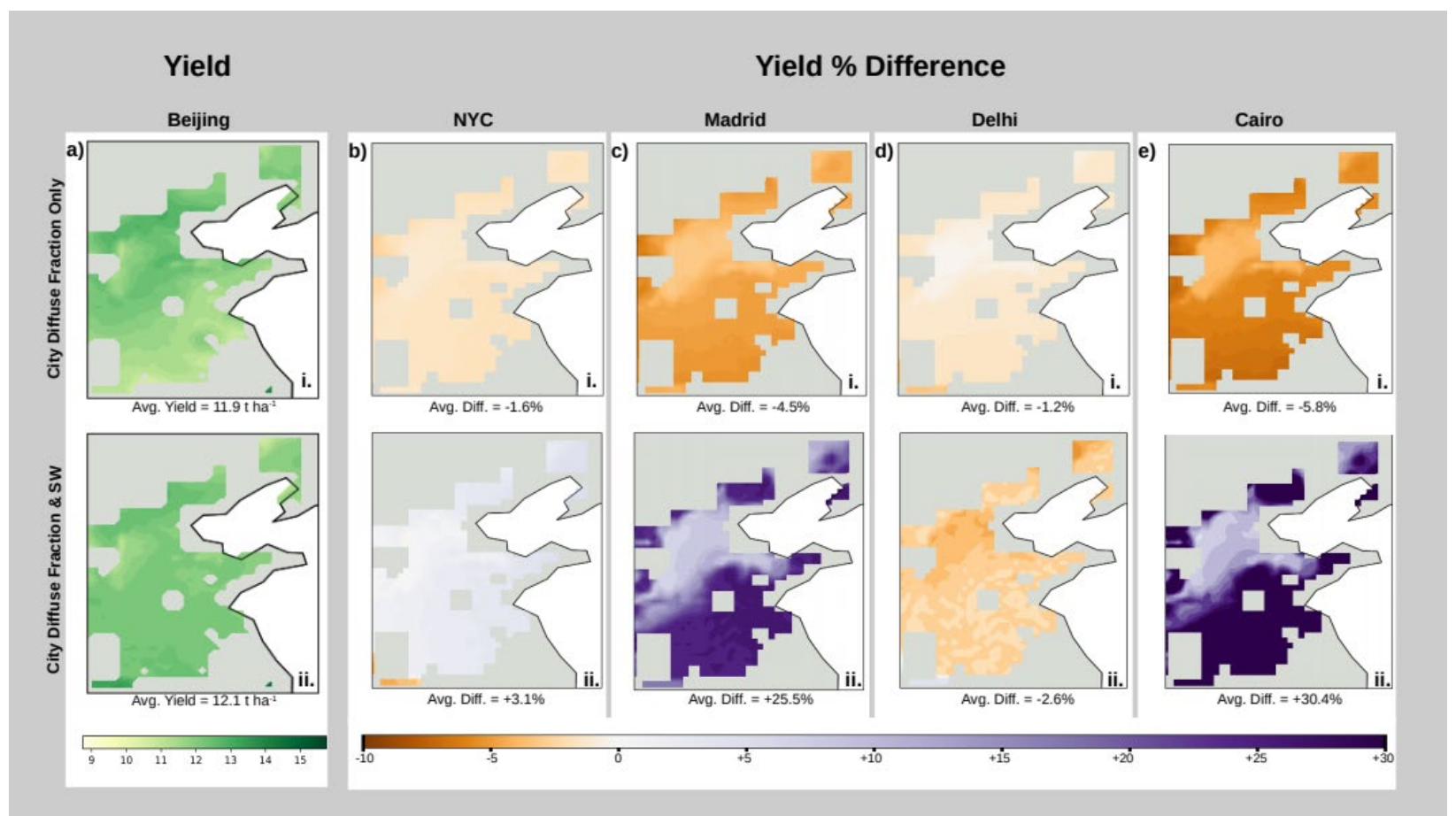

433

434 435

436

437

438

439

440

441

442 443

Figure 3) a) Yields (t ha-1) for city radiation profile simulations i. BJG_Diff and ii. BJG_SW_Diff. Fig1.b-e) percentage difference between i. <CITY>_Diff and BJG_Diff, and ii. <CITY_SW_Diff and BJG_SW_Diff, for b) New York, c) Madrid, d) Delhi and e) Cairo.

Simulations using city-modified diffuse fractions (i.e. those generated using the relationship between total SW and diffuse fraction at each city, Figure 4.c-f.i.) showed a negligible reduction in yield compared to BJG_mod_Diff (Figure 4.c-f.ii.). Furthermore, yields simulated using SW derived from the relationships for Madrid, Cairo and Delhi (Figure 4.d-f.ii), are lower than those for BJG_mod_SW, with reductions of 35, 32 and $18 \%$ respectively. This can be explained in each case by lower total SW in that location for the diffuse fractions found on the NCP. In contrast to the other city regions, modified SW from New York increased yields by an average of 5.9\% (Figure 4.c.ii). as SW in New York is higher for a given diffuse fraction in the NCP. 


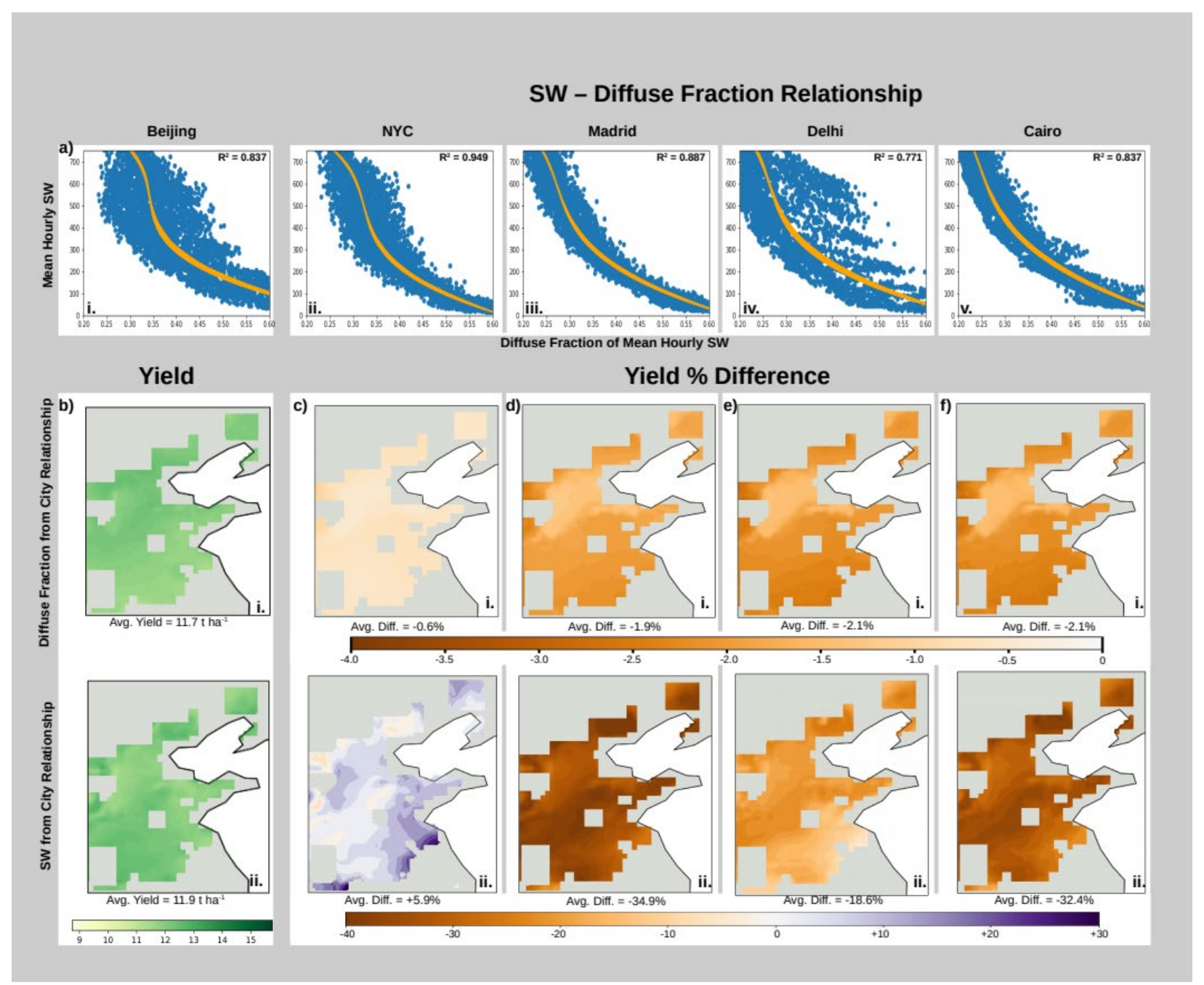

Figure 4.a.i-v) Relationships between SW and Diffuse fraction for each city, with data points in blue and quadratic regression line in 445 orange.

446 Figure 4) b) Yields for CITY_MOD radiation profile simulation. BJG_Mod_SW and ii. BJG_Mod_Diff

447 Figure 4.c-f) percentage difference between i. $\langle$ CITY >_Mod_Diff and BJG-Mod_Diff and ii. $\langle$ CITY $>$ _Mod_SW and BJG_Mod_SW,

448 for c) New York, d) Madrid, e) Delhi and f) Cairo.

\section{Discussion}

\subsection{PM influences Maize Yields}

The timing of changes in radiation relative to the developmental stage has the greatest impact during the early reproductive phase. This result has key implications for the nature and timing of emission reductions which may have greatest impact for yield crop yields on the NCP. In line with field observations, the photosynthetic capacity and hence carbon assimilation rate of maize in JULES-crop increases with leaf area during the vegetative development stage, peaking during the late vegetative stage, and remaining 
high during the early reproductive stage. However, at the start of the early reproductive phase, the maize

457

458

459

460

461

462

463

464

465

466

467

468

469

470

471

472

473

474

475

476

477

478

479

480

481

482

483

484

485

plant has matured, and therefore carbon allocation is diverted from stem, leaf and root to the harvestable portion. Our analyses demonstrate that the maize crop is most sensitive to reductions in SW (linked to elevated diffuse fraction) during the early reproductive phase (DEV3_1.5) (see Table 1). Similarly, the greatest predicted increase in yield results from reductions in diffuse fraction (i.e. reduced PM) in the early reproductive phase (simulation DEV3_0.5, Table 1), which occurs during July in our modelled maize season. As discussed earlier, at this time of year, PM concentration is at a minimum but AOD reaches a maximum in the NCP due to prevailing meteorology interacting with PM pollution to produce haze (Qu et al., 2016). Whilst this indicates a smaller contribution from AOD to SW variability during this period, our analyses demonstrated that aerosol still contributes $32 \%$ of the total variability in SW during the early reproductive phase, i.e. PM still exerts an important influence on SW during this period. The remaining variation not due to cloud and aerosol simply originates from variations in latitude and altitude across the $\mathrm{NCP}$, alongside seasonal variation in incoming radiation. The relatively small change in the AOD - SW relationship between seasons despite large changes in PM concentration and composition highlights the importance of using AOD as a measure of the impact of PM, rather than simply using PM concentration.

The complex interplay of PM and meteorology, alongside factors such as PM speciation and size distribution, it impossible to predict how increases or decreases in bulk PM concentration will affect crop yield. PM pollution at a given time of year can thus have a disproportionate impact relative to its concentration. To increase crop yields, then, policymakers should make targeted emission reductions during the early reproductive phase of regional crops when reduced PM concentrations may be expected to have a far greater impact on yields than at other times of year.

PM concentration in the NCP fell by $\sim 30 \%$ between 2013 and 2017 (Zhai et al., 2019) following the Chinese Government's introduction of the "Action Plan on the Prevention and Control of Air Pollution" in 2013. Despite these reductions, annual average PM2.5 concentrations for the Beijing-Tianjin-Hebei region were still well above national and international annual mean guidelines of $35 \mathrm{\mu g} \mathrm{m}^{-3}$ and $10 \mu \mathrm{g} \mathrm{m}^{-3}$ respectively (China: Air Quality Standards | Transport Policy, 2013; WHO, 2015), whilst recurrent haze events remain a pressing issue limiting visibility and reducing total SW at the surface (Guo et al., 2014; An et al., 2019; Zeng et al., 2019). Although PM pollution is decreasing on the NCP, our simulations suggest that the relatively high PM concentrations still present will continue to limit potential maize yield. 
Average maize yield increased by as much as $29 \%$ (Figure 3b-c, e.ii., Table 1) when the climatological average total SW and diffuse fraction at Madrid, New York or Cairo, which have lower average PM concentrations than Beijing, are applied across the NCP. Conversely, when light conditions from Delhi are applied, average maize yields remain virtually unchanged. We ascribe these effects to the combination of
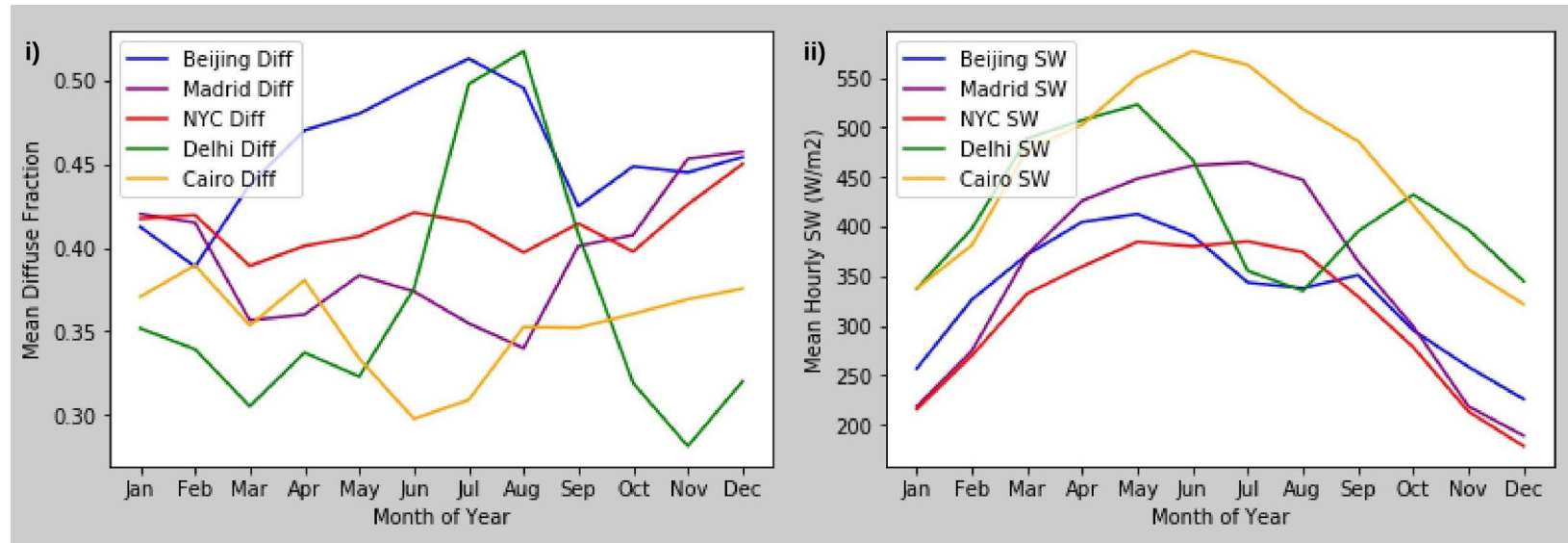

Figure 5. i) Average monthly diffuse fraction for Beijing, Madrid, New York, Delhi and Cairo. ii) Average hourly downward SW radiation per month for Beijing, Madrid, New York, Delhi and Cairo.

Heavy cloud cover associated with the Indian monsoon reduces total SW in Delhi in July and August

500 (Figure 5.i.). Although partially compensated by a large increase in diffuse fraction, the net effect is still a reduction in maize yields across the NCP. The higher SW and lower diffuse fraction seen during the rest of the year do not fully compensate the changes in light profile during this critical period. Whilst the changes at Delhi are driven by seasonal increases in cloud cover, modelling studies suggest that despite the increase in wet deposition from increased rainfall in this time period, anthropogenic and natural aerosol do contribute to the reduction in total SW (Kuhlmann and Quaas, 2010). This reduction during the period corresponding to the early and late reproductive phase has greater impact on maize yield than the higher SW during the rest of the growing season, in line with the results from our development stage 
Reducing aerosol pollution at this time of year would therefore increase light intensity for crop

511 photosynthesis. Interventions during less developmentally critical stages may have smaller effects than a

512 similar magnitude of intervention carried out during the early crop reproductive stage.

\section{4.3 How PM might change Radiation in the Future}

514 Despite similar annual mean PM concentrations in Madrid and New York (Karanasiou et al., 2014; Peltier 515 et al., 2011), there are large differences in yield between simulations driven with SW and diffuse fraction 516 from Madrid (MAD_Diff_SW) and New York (New York_Diff_SW). This yield gap is the result of $20 \%$

517 higher mean SW in Madrid than New York during the growing season (Figure 5) which is driven by 518 differences in meteorology, including cloud cover, between the two locations. The meteorology of the 519 NCP encourages formation of fog as well as haze, driven by the high relative humidity (Quan et al., 2011; 520 Gao et al., 2015; Yang et al., 2020). Given the higher average ambient SW at Madrid than in the NCP 521 throughout the entire year, it is likely that yield increase is not solely attributable to PM, and that reduced

522 NCP PM concentrations would result in more modest yield gains than those seen in MAD_SW_Diff. Given 523 New York's more comparable SW profile during the growing season, excepting the critical months of July 524 and August, application of New York SW and diffuse fraction (New York_SW_Diff) may provide a more 525 realistic future scenario for the NCP if July and August AOD could be reduced through reductions in PM 526 concentrations. Though such increases would be relatively small, as differences in daylength and cloud cover have more substantive effects, the 3\% rise in yields seen for New York_SW_Diff would equate to a gain of approximately $8 \mathrm{Mt}$ of maize nationwide, sufficient to offset the maize annually imported by China (FAOSTAT 2020), so increasing both national and global food security while increasing economic wellbeing of NCP farmers.

Contrastingly, if PM pollution intensifies across the NCP during the late vegetative or early reproductive phase, yields may further decline. As seen from simulations using Delhi SW and diffuse fraction, the drop in light intensity during July and August reduces yields, despite a $\sim 12 \%$ higher average growing season SW in Delhi than Beijing. Although Delhi's annual decrease in light intensity during DEV3 is mainly 
537

538

539

540

541

542

543

544

545

546

547

548

549

550

551

552

553

554

555

556

557

558

559

560

561

562

563

564

565

radiation, similar in magnitude to the seasonal reduction in SW seen in Delhi, were to occur in the NCP, it would be detrimental to crop yields in the region. Secondly, although reductions in SW radiation have most impact during DEV3, they also reduce plant growth at other development stages, as found in simulations DEV1_1.5 and DEV2_1.5. It is likely that increasing PM concentrations in Delhi and its surrounding regions have reduced crop yields in the Indo-Gangetic Plains in recent years (Burney and Ramanathan, 2014; Mina et al., 2018b). Any reversion to higher PM emissions on the NCP would likely have a similar effect.

Furthermore, the Delhi and New York simulations demonstrate that reductions in PM during the vegetative or late reproductive phases would likely have little impact on yields overall. Increased SW in Delhi, and decreased SW in New York during these time periods does not outweigh the impact of changes in SW during the early reproductive phase. The particular timing of changes in PM then, is especially impactful. Increased total SW during the crop vegetative stage or the late reproductive stage would not be sufficient to significantly increase yields if PM pollution remained high during the early reproductive phase. Similarly, we see in New York that elevated SW during the early reproductive phase may be sufficient to compensate, or even increase, yields if PM remained high at other times of year.

\subsection{Comparison to previous studies}

Our results highlight the key role of the timing of changes to PM pollution relative to crop development stage, while adding further evidence to a growing body of research describing the net negative impact of PM pollution upon crop yields. Whilst a number of modelling studies suggest there exists an optimum diffuse fraction for growth and yield, we do not see this for the range of diffuse fractions realistic of those observed across the NCP. We attribute this to the strength of the non-linear negative relationship between diffuse fraction and total SW, and further link this to changes in AOD and PM.

The timing of changes in PM concentration, size distribution and composition is an understudied aspect of PM impacts on crop yield. We find that the effect from increased SW is greatest during the early reproductive stage, when crops allocate carbon to seed. Our analysis of light profiles from a range of city regions further emphasises the time dependency of PM impacts. This novel analysis stresses the need for targetted intervention by policy makers trying to achieve higher yields by reducing PM, and highlights 
567 early reproductive stage for crops in different world regions.

\subsection{Uncertainties and Future of Maize Yields on the NCP}

570 Factors other than light intensity and the ratio of diffuse to direct light influence crop production. To

571 remove water stress, a key environmental stressor, as a confounding factor we assumed the region

572 irrigated as reported to be the predominant practice (Yang et al. 2015). This assumption enables us to

573 study light effects in isolation. Additional validation of modelled yields against reported harvests for the

574 NCP would enable maize in JULES-Crop to be parameterised for region-specific maize varieties and

575 agronomic practice, e.g. irrigation regimes and crop losses during harvesting, increasing confidence in

576 our model projections of actual yield. Whilst JULES-crop includes a general parameterisation for crop

577 response to changes in the diffuse fraction of SW radiation, future research is required to establish the

578 specific response of a maize canopy. However, given the dominance of the impact of changes in SW on

579 crop yields over changes in diffuse fraction seen here, we would expect only minor changes in projected

580 crop loss as a result.

581

582 Similarly, our analysis relies upon the strength of the reanalysis data provided by ERA-5. Whilst a

583 significant proportion of these data are model- rather than observation- derived, this dataset represents a

584 significant step forward from similar reanalysis datasets (Copernicus Climate Change Service (C3S),

585 2017; Urraca et al., 2018) $\square$, and provides radiation data comparable to satellite retrievals. A recent review

586 identifies an underestimate of diffuse light by ERA-5 compared to some satellite retrievals (Jiang, Yang,

587 Wang, Bai, \& Bai, 2020) $\square$ but the sparse ground measurement sites used within that study demonstrate

588 the need for large-scale reanalysis data to be used for modelling studies addressing a large geographical

589 region. Only two ground stations used by these authors lie within our model domain. Given our use of

590 climatologically averaged data to drive our model, we feel confident that the ERA-5 dataset represents

591 the most useful assessment of surface radiation for our purposes and is suitable for use over the

592 geographical and temporal scales of our simulations.

593

594 A positive contribution from diffuse radiation to plant photosynthesis rates has been well documented for 
tree species (Roderick et al., 2001; Niyogi et al., 2004; Mercado et al., 2009; Kanniah et al., 2012; Rap et

al., 2015), but the net impact on crop yields of increased diffuse fraction at the expense of light intensity is

less well understood. We find that the decrease in total SW associated with increasing PM concentrations

far outweighs any possible fertilisation effect of increased diffuse fraction. Breeding programmes have

already delivered substantial increases in leaf angles in the upper canopy of maize, increasing light penetration to the lower canopy such that maize might be expected to benefit less from diffuse light fertilisation than tree species (Hammer et al. 2009; Zhu et al. 2010). We find that the decrease in total SW associated with increasing PM concentrations far outweighs any possible fertilisation effect of increased diffuse fraction. Elevated PM during the early reproductive stage (i.e. flowering and pod filling) would be particularly detrimental to crop development, with a $50 \%$ increase in diffuse fraction during this period reducing yield by an average of $37 \%$ due to the accompanying reduction in SW. Although cloud cover plays a greater role in the attenuation of SW radiation than PM, our analysis of AOD and total cloud cover demonstrates that aerosol contributes a third of the observed change in SW. Our sensitivity analyses based on light intensity and diffuse fraction over New York suggests that an increase in maize yields of up to $3.5 \%$ may be realistic for NCP if PM concentrations were to be reduced to those of New York. This will, however, depend on the concomitant changes in particle size and composition, which further affect the relationship between diffuse fraction and total SW, and which require fuller investigation for future emission reduction scenarios

614 One of the largest causes of uncertainty over future maize yields on the NCP is the interaction of PM and ozone pollution. As PM pollution has decreased in the NCP, ozone pollution has increased (Zeng et al., 616 2019), and while this principally reflects a reduction in $\mathrm{NO}_{x}$ emissions, it has also been partly attributed to 617 increased light intensity increasing the rate of photochemical formation of ozone (Li et al., 2019). Elevated concentrations of ozone were estimated to have decreased maize yields across the USA by $\sim 10 \%$ between 1980 and 2011 (McGrath et al., 2015). Yield gains from reductions in PM pollution in the NCP

620 may therefore be offset or outweighed by losses due to rising ozone concentrations, and it will be critical 621 to determine how the two interact. It is imperative that future emissions reduction strategies address PM 622 and ozone pollution together. 


\section{Funding Sources}

624

625

626

627

628

629

630

631

632

633

634

635

636

637

638

639

640

641

642

643

644

645

646

647

M. Wolffe is grateful to the Royal Society of London for funding his PhD Studentship (RGFIEAI180129).

K. Ashworth is a Royal Society Dorothy Hodgkin Fellow and thanks the Royal Society of London for their support and funding (DH150070).

\section{References}

Alton, P. B. (2008). Reduced carbon sequestration in terrestrial ecosystems under overcast skies compared to clear skies. Agricultural and Forest Meteorology, 148(10), 1641-1653. https://doi.org/10.1016/J.AGRFORMET.2008.05.014

ALTON, P. B., NORTH, P. R., \& LOS, S. O. (2007). The impact of diffuse sunlight on canopy lightuse efficiency, gross photosynthetic product and net ecosystem exchange in three forest biomes. Global Change Biology, 13(4), 776-787. https://doi.org/10.1111/j.1365-2486.2007.01316.x

An, Z., Huang, R. J., Zhang, R., Tie, X., Li, G., Cao, J., ... Ji, Y. (2019). Severe haze in northern China: A synergy of anthropogenic emissions and atmospheric processes. Proceedings of the National Academy of Sciences of the United States of America. https://doi.org/10.1073/pnas.1900125116

Aziz, R. M., Zabawi, A. G. M., Azdawiyah, A. T. S., \& Fazlyzan, A. (2019). Effects of haze on net photosynthetic rate , stomatal conductance and yield of Malaysian rice ( Oryza sativa L .) varieties. Journal of Agricultural and Food Science, 47(1), 1-13.

Best, M. J., Pryor, M., Clark, D. B., Rooney, G. G., Essery, R. . L. H., Ménard, C. B., .. Harding, R. J. (2011). The Joint UK Land Environment Simulator (JULES), model description - Part 1: Energy and water fluxes. Geoscientific Model Development, 4(3), 677-699. https://doi.org/10.5194/gmd-4$677-2011$

Boman, J., Shaltout, A. A., Abozied, A. M., \& Hassan, S. K. (2013). On the elemental composition of $\mathrm{PM}_{2.5}$ in central Cairo, Egypt. X-Ray Spectrometry, 42(4), 276-283. https://doi.org/10.1002/xrs.2464 

in leaves? Functional Plant Biology, 37(5), 403. https://doi.org/10.1071/FP09262

650

Burney, J., \& Ramanathan, V. (2014). Recent climate and air pollution impacts on Indian agriculture. Proceedings of the National Academy of Sciences of the United States of America, 111(46), 1631916324. https://doi.org/10.1073/pnas.1317275111

Chameides, W. L., Yu, H., Liu, S. C., Bergin, M., Zhou, X., Mearns, L., ... Giorgi, F. (1999). Case study of the effects of atmospheric aerosols and regional haze on agriculture: An opportunity to enhance crop yields in China through emission controls? Proceedings of the National Academy of Sciences of the United States of America. https://doi.org/10.1073/pnas.96.24.13626

Chen, H., Wang, H., 2015. Haze days in North China and the associated atmospheric circulations based on daily visibility data from 1960 to 2012 . J. Geophys. Res. https://doi.org/10.1002/2015JD023225Cheng, Z., Wang, S., Jiang, J., Fu, Q., Chen, C., Xu, B., ... Hao, J. (2013). Long-term trend of haze pollution and impact of particulate matter in the Yangtze River Delta, China. Environmental Pollution. https://doi.org/10.1016/j.envpol.2013.06.043

Cheng, S. J., Bohrer, G., Steiner, A. L., Hollinger, D. Y., Suyker, A., Phillips, R. P., \& Nadelhoffer, K. J. (2015). Variations in the influence of diffuse light on gross primary productivity in temperate ecosystems. Agricultural and Forest Meteorology, 201, 98-110. https://doi.org/10.1016/J.AGRFORMET.2014.11.002

China: Air Quality Standards | Transport Policy. (2013). Retrieved May 18, 2020, from https://www.transportpolicy.net/standard/china-air-quality-standards/

Clark, D. B., Mercado, L. M., Sitch, S., Jones, C. D., Gedney, N., Best, M. J., ... Cox, P. M. (2011). The Joint UK Land Environment Simulator (JULES), Model description - Part 2: Carbon fluxes and vegetation. Geoscientific Model Development Discussions, 4(1), 641-688. https://doi.org/10.5194/gmdd-4-641-2011

Cohan, D. S., Xu, J., Greenwald, R., Bergin, M. H., \& Chameides, W. L. (2002). Impact of atmospheric aerosol light scattering and absorption on terrestrial net primary productivity. Global Biogeochemical Cycles, 16(4), 37-1-37-12. https://doi.org/10.1029/2001GB001441 

reanalyses of the global climate. Copernicus Climate Change Service Climate Data Store (CDS). agriculture in high crop productivity regions. CURRENT SCIENCE (Vol. 98).

679 Dohleman, F.G., Long, S.P., 2009. More productive than maize in the Midwest: How does Miscanthus do it? Plant Physiol. https://doi.org/10.1104/pp.109.139162

FAOSTAT. (n.d.-a). Retrieved April 2, 2020, from

682

http://www.fao.org/giews/countrybrief/country.jsp?code=CHN

FAOSTAT. (n.d.-b). FAOSTAT Crop Database. Retrieved November 30, 2018, from

684 http://www.fao.org/faostat/en/\#data/QC

FAOSTAT. (n.d.-c. FAOSTAT Crop Database. Retrieved September, 2020, from http://www.fao.org/faostat/en/\#data/QC

687

Feng, Z., Hu, E., Wang, X., Jiang, L., Liu, X., 2015. Ground-level O 3 pollution and its impacts on 688

689 food crops in China : A review. Environ. Pollut. 199, 42-48. https://doi.org/10.1016/j.envpol.2015.01.016

Gao, Y., Zhang, M., Liu, Z., Wang, L., Wang, P., Xia, X., ... Zhu, L. (2015). Modeling the feedback between aerosol and meteorological variables in the atmospheric boundary layer during a severe Gorai, A.K., Tchounwou, P.B., Biswal, S.S., Tuluri, F., 2018. Spatio-Temporal Variation of Particulate Matter(PM2.5) Concentrations and Its Health Impacts in a Mega City, Delhi in India. fog-haze event over the North China Plain. Atmospheric Chemistry and Physics. https://doi.org/10.5194/acp-15-4279-2015 Environ. Health Insights 12. https://doi.org/10.1177/1178630218792861

Government, M. of E. and F. (2012). Energy Statistics. China Statistical Yearbook. https://doi.org/Twenty first issue Greenwald, R., Bergin, M. H., Xu, J., Cohan, D., Hoogenboom, G., \& Chameides, W. L. (2006). The 

Systems. https://doi.org/10.1016/j.agsy.2005.10.004

702

703

704

705

706

707

708

709

710

711

712

713

714

715

716

717

718

719

720

721

722

723

724

Gu, L., Baldocchi, D., Verma, S. B., Black, T. A., Vesala, T., Falge, E. M., \& Dowty, P. R. (2002). Advantages of diffuse radiation for terrestrial ecosystem productivity. Journal of Geophysical Research Atmospheres, 107(5-6), ACL 2-1. https://doi.org/10.1029/2001jd001242

Guo, S., Hu, M., Zamora, M. L., Peng, J., Shang, D., Zheng, J., ... Zhang, R. (2014).

I Change Biology, 24(3), 987-1000. https://doi.org/10.1111/gcb.13898

Han, S., Bian, H., Zhang, Y., Wu, J., Wang, Y., Tie, X., .. Yao, Q. (2012). Effect of aerosols on visibility and radiation in spring 2009 in Tianjin, China. Aerosol and Air Quality Research. https://doi.org/10.4209/aaqr.2011.05.0073

Hu, X., \& Zimmer, Y. (2013). China's Corn Production.

Hua, Y., Cheng, Z., Wang, S., Jiang, J., Chen, D., Cai, S., .. Yu, J. (2015). Characteristics and source apportionment of PM2.5 during a fall heavy haze episode in the Yangtze River Delta of China. Atmospheric Environment. https://doi.org/10.1016/j.atmosenv.2015.03.046

Huang, K., Wang, S., Zhou, L., Wang, H., Zhang, J., Yan, J., ... Shi, P. (2014). Impacts of Diffuse Radiation on Light Use Efficiency across Terrestrial Ecosystems Based on Eddy Covariance Observation in China. PLoS ONE, 9(11), e110988. https://doi.org/10.1371/journal.pone.0110988

Huang, R.-J., Zhang, Y., Bozzetti, C., Ho, K.-F., Cao, J.-J., Han, Y., ... Prévôt, A. S. H. (2014). High secondary aerosol contribution to particulate pollution during haze events in China. Nature, 514(7521), 218-222. https://doi.org/10.1038/nature13774

Jain, S.L., Arya, B.C., Kumar, A., Ghude, S.D., Kulkarni, P.S., 2005. Observational study of surface ozone at New Delhi, India. Int. J. Remote Sens. https://doi.org/10.1080/01431160500076616 Jiang, H., Yang, Y., Wang, H., Bai, Y., \& Bai, Y. (2020). Surface diffuse solar radiation determined by reanalysis and satellite over East Asia: Evaluation and comparison. Remote Sensing. https://doi.org/10.3390/RS12091387 
Just, A. C., Wright, R. O., Schwartz, J., Coull, B. A., Baccarelli, A. A., Tellez-Rojo, M. M., ... Kloog, I. (2015). Using High-Resolution Satellite Aerosol Optical Depth To Estimate Daily PM2.5 Geographical Distribution in Mexico City. Environmental Science \& Technology, 49(14), 8576-8584. https://doi.org/10.1021/acs.est.5b00859 diffuse radiation and terrestrial plant productivity: A review. Progress in Physical Geography. https://doi.org/10.1177/0309133311434244 Karanasiou, A., Querol, X., Alastuey, A., Perez, N., Pey, J., Perrino, C., ... Pascal, M. (2014). Particulate matter and gaseous pollutants in the Mediterranean Basin: Results from the MEDAgricultural and Forest Meteorology. https://doi.org/10.1016/j.agrformet.2019.02.037

PARTICLES project. Science of the Total Environment.

https://doi.org/10.1016/j.scitotenv.2014.04.096

Kimball, B. A., Boote, K. J., Hatfield, J. L., Ahuja, L. R., Stockle, C., Archontoulis, S., ... Williams, K. (2019). Simulation of maize evapotranspiration: An inter-comparison among 29 maize models. concentrations in an urban area in greater Cairo. Environ. Monit. Assess. https://doi.org/10.1007/s10661-008-0208-7

Kuhlmann, J., \& Quaas, J. (2010). How can aerosols affect the Asian summer monsoon? Assessment during three consecutive pre-monsoon seasons from CALIPSO satellite data. Atmospheric Chemistry and Physics. https://doi.org/10.5194/acp-10-4673-2010

LEI, H.-M., \& YANG, D.-W. (2009). Seasonal and interannual variations in carbon dioxide exchange over a cropland in the North China Plain. Global Change Biology, 16(11), no-no. https://doi.org/10.1111/j.1365-2486.2009.02136.x Li, H., Jiang, D., Wollenweber, B., Dai, T., \& Cao, W. (2010). Effects of shading on morphology, physiology and grain yield of winter wheat. European Journal of Agronomy, 33(4), 267-275. https://doi.org/10.1016/J.EJA.2010.07.002 

Biology (pp. 563-576). Springer New York. https://doi.org/10.1007/978-0-387-79418-1_28 Li, K., Jacob, D. J., Liao, H., Shen, L., Zhang, Q., \& Bates, K. H. (2019). Anthropogenic drivers of 2013-2017 trends in summer surface ozone in China. Proceedings of the National Academy of Sciences of the United States of America. https://doi.org/10.1073/pnas.1812168116

Li, T., \& Yang, Q. (2015). Advantages of diffuse light for horticultural production and perspectives for further research. Frontiers in Plant Science, 6, 704. https://doi.org/10.3389/fpls.2015.00704 to crop production in the North China Plain, since 1980s. Global Change Biology, 16(8), 2287-2299. https://doi.org/10.1111/j.1365-2486.2009.02077.x changes the linear relationship between photosynthesis and stomatal conductance and decreases water use efficiency in rice. Sci. Total Environ. https://doi.org/10.1016/J.SCITOTENV.2018.11.132 of ozone damage to historical maize and soybean yields in the United States. https://doi.org/10.1073/pnas.1509777112 Impact of changes in diffuse radiation on the global land carbon sink. Nature, 458(7241), 1014Mina, U., Chandrashekara, T. K., Kumar, S. N., Meena, M. C., Yadav, S., Tiwari, S., ... Kumar, R. (2018a). Impact of particulate matter on basmati rice varieties grown in Indo-Gangetic Plains of Mina, U., Chandrashekara, T. K., Kumar, S. N., Meena, M. C., Yadav, S., Tiwari, S., .. Kumar, R. (2018b). Impact of particulate matter on basmati rice varieties grown in Indo-Gangetic Plains of India: Growth, biochemical, physiological and yield attributes. Atmospheric Environment, 188, 174- 

Biol. Sci. https://doi.org/10.1098/rstb.1977.0140

780

781

782

783

784

785

786

787

788

789

790

791

792

793

794

795

796

797

798

799

800

801

802

Moosmüller, H., Chakrabarty, R. K., \& Arnott, W. P. (2009, July 1). Aerosol light absorption and its measurement: A review. Journal of Quantitative Spectroscopy and Radiative Transfer. Pergamon. https://doi.org/10.1016/j.jqsrt.2009.02.035

Niyogi, D., Chang, H., Saxena, V. K., Holt, T., Alapaty, K., Booker, F., ... Xue, Y. (2004). Direct observations of the effects of aerosol loading on net ecosystem $\mathrm{CO}_{2}$ exchanges over different landscapes. Geophysical Research Letters, 31(20), L20506. https://doi.org/10.1029/2004GL020915

Ojha, N., Sharma, A., Kumar, M., Girach, I., Ansari, T. U., Sharma, S. K., ... Gunthe, S. S. (2020). On the widespread enhancement in fine particulate matter across the Indo-Gangetic Plain towards winter. Scientific Reports, 10(1), 1-9. https://doi.org/10.1038/s41598-020-62710-8

Ort, D.R., Merchant, S.S., Alric, J., Barkan, A., Blankenship, R.E., Bock, R., Croce, R., Hanson, M.R., Hibberd, J.M., Long, S.P., Moore, T.A., Moroney, J., Niyogi, K.K., Parry, M.A.J., PeraltaYahya, P.P., Prince, R.C., Redding, K.E., Spalding, M.H., Van Wijk, K.J., Vermaas, W.F.J., Von Caemmerer, S., Weber, A.P.M., Yeates, T.O., Yuan, J.S., Zhu, X.G., 2015. Redesigning photosynthesis to sustainably meet global food and bioenergy demand. Proc. Natl. Acad. Sci. U. S. A. https://doi.org/10.1073/pnas.1424031112

Osborne, T., Gornall, J., Hooker, J., Williams, K., Wiltshire, A., Betts, R., \& Wheeler, T. (2015). JULES-crop: a parametrisation of crops in the Joint UK Land Environment Simulator. Geoscientific Model Development, 8(4), 1139-1155. https://doi.org/10.5194/gmd-8-1139-2015

Peltier, R. E., Cromar, K. R., Ma, Y., Fan, Z. H., \& Lippmann, M. (2011). Spatial and seasonal distribution of aerosol chemical components in New York City: (2) Road dust and other tracers of traffic-generated air pollution. Journal of Exposure Science and Environmental Epidemiology. https://doi.org/10.1038/jes.2011.15

Proctor, J., Hsiang, S., Burney, J., Burke, M., \& Schlenker, W. (2018). Estimating global agricultural 

https://doi.org/10.1038/s41586-018-0417-3 concentrations from MODIS over Yangtze River Delta of China during 2014-2017. Atmospheric Environment, 195, 149-158. https://doi.org/10.1016/J.ATMOSENV.2018.09.054 optical depth and the surface particulate matter concentration over the north China Plain. Atmospheric Environment, 127, 90-99. https://doi.org/10.1016/j.atmosenv.2015.11.061

Quan, J., Zhang, Q., He, H., Liu, J., Huang, M., \& Jin, H. (2011). Analysis of the formation of fog and haze in North China Plain (NCP). Atmospheric Chemistry and Physics. https://doi.org/10.5194/acp$11-8205-2011$

Ramanathan, V., Crutzen, P. J., Kiehl, J. T., \& Rosenfeld, D. (2001). Atmosphere: Aerosols, climate, and the hydrological cycle. Science. https://doi.org/10.1126/science.1064034

Rap, A., Scott, C. E., Reddington, C. L., Mercado, L., Ellis, R. J., Garraway, S., ... Spracklen, D. V. (2018). Enhanced global primary production by biogenic aerosol via diffuse radiation fertilization. Nature Geoscience, 11(9), 640-644. https://doi.org/10.1038/s41561-018-0208-3

Rap, A., Spracklen, D. V., Mercado, L., Reddington, C. L., Haywood, J. M., Ellis, R. J., ... Butt, N. (2015). Fires increase Amazon forest productivity through increases in diffuse radiation. Geophysical Research Letters, 42(11), 4654-4662. https://doi.org/10.1002/2015GL063719

Roderick, M. L., Farquhar, G. D., Berry, S. L., \& Noble, I. R. (2001a). On the direct effect of clouds and atmospheric particles on the productivity and structure of vegetation. Oecologia, 129(1), 21-30. https://doi.org/10.1007/s004420100760

Roderick, M. L., Farquhar, G. D., Berry, S. L., \& Noble, I. R. (2001b). On the direct effect of clouds and atmospheric particles on the productivity and structure of vegetation, 21-30.

https://doi.org/10.1007/s004420100760 

global patterns. Global Ecology and Biogeography. https://doi.org/10.1111/j.14668238.2010.00551.x concentration trends and its relationship with weather types in Spain (2001-2010). Atmos. Environ. https://doi.org/10.1016/j.atmosenv.2014.11.005

Shen, R., Schäfer, K., Schnelle-Kreis, J., Shao, L., Norra, S., Kramar, U., ... Emeis, S. (2018). Seasonal variability and source distribution of haze particles from a continuous one-year study in Beijing. Atmospheric Pollution Research. https://doi.org/10.1016/j.apr.2017.12.013 Shihuang, Z., \& Kaijian, H. (2010). Maize and the formal agricultural research and development system: evolution, challenges and alternatives. In Seeds and Synergies (pp. 13-28). Practical Action Publishing. https://doi.org/10.3362/9781780440330.002 in a case-crossover analysis of childhood asthma hospital visits in New York City. Environ. Res. https://doi.org/10.1016/j.envres.2016.01.020 productivity in the eastern United States. Atmospheric Environment, 122, 463-476. https://doi.org/10.1016/j.atmosenv.2015.09.051

\section{Timsina, J. (2012). Review of rice-wheat in IGP-Advances in Agronomy (Vol. 117). Elsevier Inc.} Retrieved from https://www.academia.edu/9776292/Review_of_rice-wheat_in_IGP_Advances_in_Agronomy 
Wang, H., Tian, M., Li, X., Chang, Q., Cao, J., Yang, F., ... He, K. (2015). Chemical Composition and Light Extinction Contribution of PM2.5 in Urban Beijing for a 1-Year Period. Aerosol and Air

WHO. (2015). WHO | Ambient (outdoor) air quality and health. Retrieved from https://web.archive.org/web/20160104165807/http://www.who.int/mediacentre/factsheets/fs313/en/

Wickens, G. E., \& Horn, H. S. (1972). The Adaptive Geometry of Trees. Kew Bulletin. https://doi.org/10.2307/4109478

Williams, K., Gornall, J., Harper, A., Wiltshire, A., Hemming, D., Quaife, T., ... Scoby, D. (2017). Evaluation of JULES-crop performance against site observations of irrigated maize from Mead, Nebraska. Geoscientific Model Development, 10(3), 1291-1320. https://doi.org/10.5194/gmd-10$1291-2017$

Xie, X., Wang, T., Yue, X., Li, S., Zhuang, B., \& Wang, M. (2020). Effects of atmospheric aerosols on terrestrial carbon fluxes and CO2 concentrations in China. Atmospheric Research, 237, 104859. https://doi.org/10.1016/J.ATMOSRES.2020.104859 pollution during the transition period between autumn and winter in Beijing, China. Science of the Total Environment. https://doi.org/10.1016/j.scitotenv.2019.134745 apportionment of PM2.5 in a background site in the North China Plain. Science of the Total $878 \quad$ Environment. https://doi.org/10.1016/j.scitotenv.2015.09.123 
Yue, X., \& Unger, N. (2017). Aerosol optical depth thresholds as a tool to assess diffuse radiation fertilization of the land carbon uptake in China. Atmospheric Chemistry and Physics, 17(2), 13291342. https://doi.org/10.5194/acp-17-1329-2017

Zeng, Y., Cao, Y., Qiao, X., Seyler, B. C., \& Tang, Y. (2019). Air pollution reduction in China: Recent success but great challenge for the future. Science of the Total Environment. https://doi.org/10.1016/j.scitotenv.2019.01.262

Zhai, S., Jacob, D. J., Wang, X., Shen, L., Li, K., Zhang, Y., ... Liao, H. (2019). Fine particulate matter (PM2.5) trends in China, 2013-2018. separating contributions from anthropogenic emissions and meteorology. Atmospheric Chemistry and Physics. https://doi.org/10.5194/acp-19-11031-2019

Zhao, L., Wang, W., Hao, T., Qu, W., Sheng, L., Luo, C., ... Zhou, Y. (2020). The autumn haze-fog episode enhanced by the transport of dust aerosols in the Tianjin area. Atmospheric Environment. https://doi.org/10.1016/j.atmosenv.2020.117669 agricultural production from 2001 to 2010. Journal of Cleaner Production, 178, 133-141. https://doi.org/10.1016/J.JCLEPRO.2017.12.204 Zhou, Luxi, Schwede, D. B., Wyat Appel, K., Mangiante, M. J., Wong, D. C., Napelenok, S. L., ... Zhang, B. (2019). The impact of air pollutant deposition on solar energy system efficiency: An approach to estimate PV soiling effects with the Community Multiscale Air Quality (CMAQ) model. Science of The Total Environment, 651, 456-465.

901 https://doi.org/10.1016/J.SCITOTENV.2018.09.194 Zhu, X.G., Long, S.P., Ort, D.R., (2010) Improving Photosynthetic Efficiency for Greater Yield. Annual Review of Plant Biology, 61, 235-261. potential effect on yield during wheat growth in the Northwest-Shandong Plain of China. JES, 34, 1- 
9. https://doi.org/10.1016/j.jes.2014.12.022 